\title{
Pedestrianisation and Politics: a Case Study
}

- June 2016

- 4750 words. 5 figures, 4 tables.

Author 1

- Dr Steve Melia MA PhD MILT

Centre for Transport and Society, University of the West of England, Bristol, UK. Author 2

- lan Shergold MA

Centre for Transport and Society, University of the West of England, Bristol, UK.

Full contact details of corresponding author.

University of the West of England

Coldharbour Lane

Bristol BS2 0JB

steve.melia@uwe.ac.uk 
Abstract (150 words)

Proposals to pedestrianise or close roads to traffic are often controversial. This article analyses the impact of partial pedestrianisation, using a case study conducted in Brighton, UK. Before and after studies found modest traffic reduction within the area and an increase in cycling during the week, but no significant overall modal shift. There was a high level of public support for the pedestrianisation. One of the streets was closed to traffic on weekends only; there was public support for this to be extended to weekdays as well. Over two thirds of visitors to the area arrived using sustainable modes; less than $3 \%$ had parked in the immediate area. The changes were controversial and contested; the outcome was a compromise. This article analyses the process and draws lessons for other cities.

\section{Keywords chosen from ICE Publishing list}

Transport planning; Traffic engineering; Local government; pedestrianization; urban design 


\section{Introduction and Context}

Pedestrianisation and traffic filtering have been widely used by municipal authorities across Europe since the 1960s as tools to reduce the impact of motor traffic on central areas with high volumes of pedestrians, to improve the urban environment, encourage modal shift towards more sustainable travel and also to benefit retail businesses. Proposals to remove rights of way or parking for motor vehicles are often controversial. Although there is some evidence that retail businesses benefit from pedestrianisation, retailers and organisations representing them often oppose such proposals when they are made. Local residents may also support or oppose proposals, which would improve their immediate environment but could also cause them inconvenience.

This article draws on a literature review conducted for a European-Union funded project (Melia, 2016) and on a case study conducted in the Old Town of Brighton, UK, where Brighton and Hove City Council planned to remove through traffic and extend pedestrianisation on some streets. Brighton and Hove has a record since the early 1990s of progressive modal shift away from car travel. Road space has been reallocated to bus lanes and cycle lanes, parking controls have been progressively extended and high density development in the central areas have often been 'car-free' or with very low parking ratios (Melia, 2015). All of these measures have been controversial; transport controversies have contributed to changes of political control of Brighton and Hove Council on several occasions in the past.

The Council commissioned the University of the West of England (UWE) to evaluate the plan, initially focussing on: traffic volumes, travel to the area and perceptions of the changes amongst businesses and the general public. The study was commissioned before all the details of the plan were finalised. The implementation process proved more challenging than the Council had originally anticipated, so what began as an evaluation of outcomes also became a study of the implementation process.

\section{$2 \quad$ Literature Review}

Considering the prevalence of pedestrianisation and traffic filtering there is surprisingly little recent evidence available, particularly from within Europe. Ex-post evaluations have tended to focus on the impact of pedestrianisation on retail spending (Hass-Klau, 1993, Chung, 2011) and modal share of travel to the pedestrianised area, whereas descriptive case studies have focussed on environmental improvements within the pedestrianised areas and sometimes on implementation processes. A related literature has sought to evaluate the impact of road closures and capacity reductions on traffic levels. 
Several studies of central area pedestrianisation schemes in individual European towns and cities have found evidence that traffic volumes fell on the surrounding streets as well as the pedestrianised streets themselves, bringing modest reductions in air pollution (Civitas Caravel, 2014, Civitas Modern, 2013). Those studies of two Spanish towns both found increased pedestrian numbers within the pedestrianised streets and modal shift in travel to and from the central areas, away from driving and towards public transport. Civitas Caravel (2014) also reported a fall of 4.5 percentage points in the share of travel by car across the whole town, although there was no attempt to control for confounding factors. Parkhurst (2003) found that pedestrianisation in Oxford, UK, was followed by a $17 \%$ reduction in traffic entering the city centre, whilst total visitor numbers remained stable; the difference was mainly due to increased bus use.

Cairns et al. (2002) found that road closures and capacity reductions, (for a range of temporary and permanent reasons including pedestrianisation) do not displace all the previous traffic volumes onto surrounding streets. Instead, much of the traffic 'disappears'. This finding, which is the inverse of 'induced traffic', was based on secondary data collected by local authorities in 10 countries (though most of the data came from the UK or Germany). Drawing mainly on professional opinions, the authors ascribe the disappearing traffic phenomenon to a range of different behavioural responses including: route changes, reduced frequency of travel, more trip chaining, modal shift, changes of destination and in the longer term changes of job or residential relocation. The scale of 'disappearing traffic' varied considerably between the case studies; the authors hypothesised that availability of spare capacity on surrounding roads would influence the balance between traffic displacement and journey reduction or modal shift. No attempt was made to control for confounding factors and as the authors did not control the data collection themselves, they could not rule out the possibility that some additional traffic was being displaced outside the areas of measurement.

Subsequent studies of (mainly temporary) road or bridge closures have provided some support for these tentative explanations (Guiver, 2011, Hunt et al., 2002, Zhu et al., 2010). One study of a permanent road removal and pedestrian improvement scheme, in Seoul, Korea, found significant modal shift from driving to public transport in the short and medium-terms (Chung et al., 2012), which was more pronounced in the areas closer to the roads removed. Melia (2015) followed up one of the cases reviewed in Cairns et al. (2002) - the Cambridge Core Traffic Scheme, which involved several stages of pedestrianisation and closures to through traffic. $\mathrm{He}$ found a long-term decline in traffic in the central areas and stable traffic levels on the radial routes, over years when the population and economy of Cambridge were both growing rapidly.

Several studies of the process of pedestrianisation and/or road closures have found considerable resistance, particularly amongst retail businesses, to proposals for pedestrianisation or road closures in central areas, followed by acceptance or positive 
endorsement after the impacts were assimilated (Hass-Klau, 1993, Melia, 2015, Hass-Klau, 2015). Groningen in the Netherlands was a pioneer in removing traffic from its city centre, starting with its closure to through traffic in 1977. This provoked opposition from business organisations, who initially lobbied unsuccessfully for the changes to be reversed (Tsubohara, 2007).

\section{Case Study Context: Brighton's Old Town Traffic Improvement Scheme}

Brighton's Old Town is a high-density historic area close to the seafront and city centre, with a mixture of shops, restaurants and flats. It includes The Lanes, with very narrow streets that were pedestrianised in 1989 (Figure 1). A section of another street was pedestrianised in 1990 but the rest of the Old Town remained open to through traffic in 2012, when Brighton and Hove Council began consulting on its proposals.

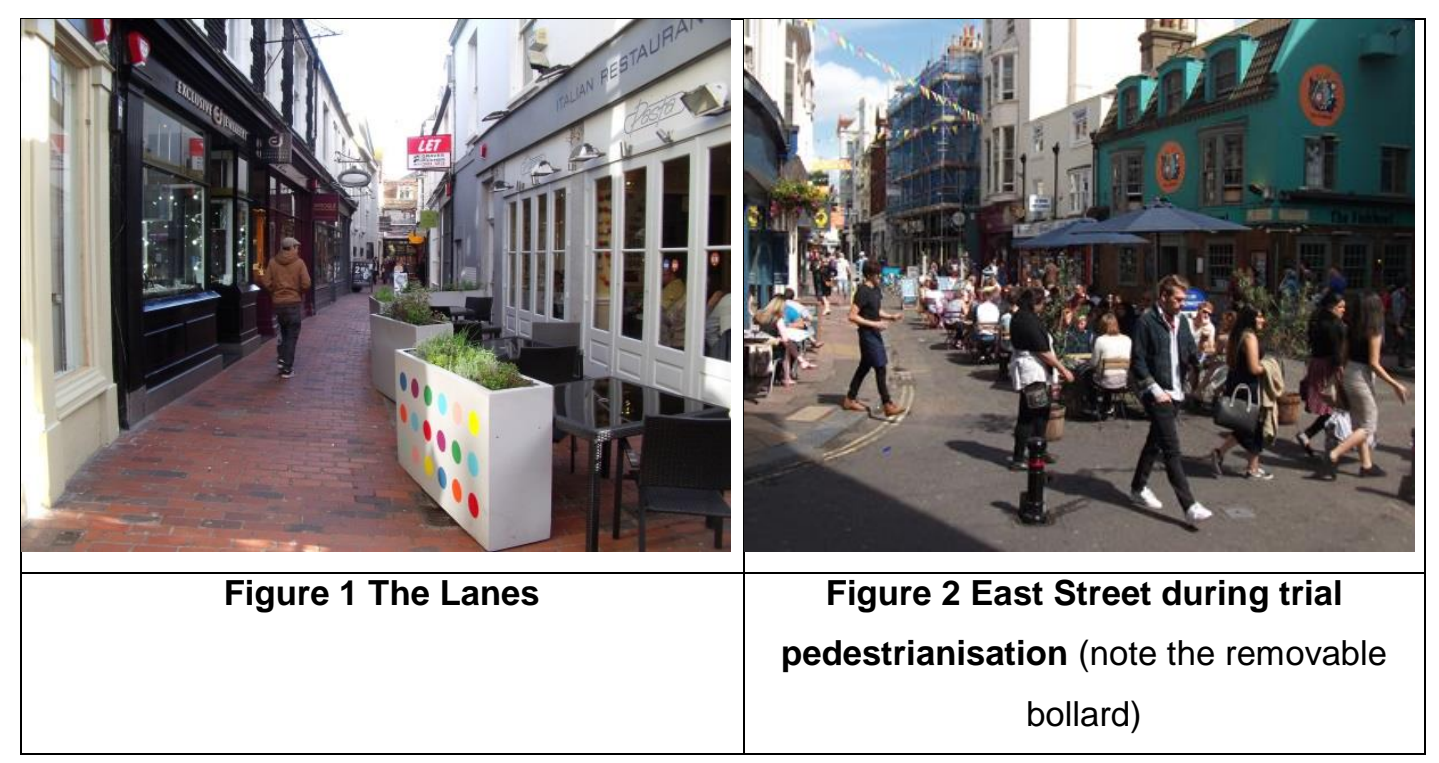

The Council's stated reasons for the initiative were that rising traffic volumes were "detracting from the character of the area"; the aims of their proposals were to "reduce the volume of traffic in the area whilst retaining access for those that require it" (Brighton \& Hove CC, 2012). An unpublished traffic survey conducted between 8am and 10am on a weekday during 2008 showed that $40 \%$ of the traffic entering the Old Town was through traffic that left the area within 5 minutes.

Figure 3 shows the proposals which were agreed by the Council after the public consultation. These proposals were controversial and following several objections were subject to a planning inquiry in 2013 , which recommended in favour of some of the changes but not others. After the inquiry, the plan was amended to address some of the inspector's concerns, following which, the Council decided to implement a more limited scheme, also shown in Figure 3, in two stages: 
1. Ship Street was closed to traffic in August 2014, (which effectively closed the area to through traffic).

2. East Street was pedestrianised at weekends in a trial scheme starting May 2015.

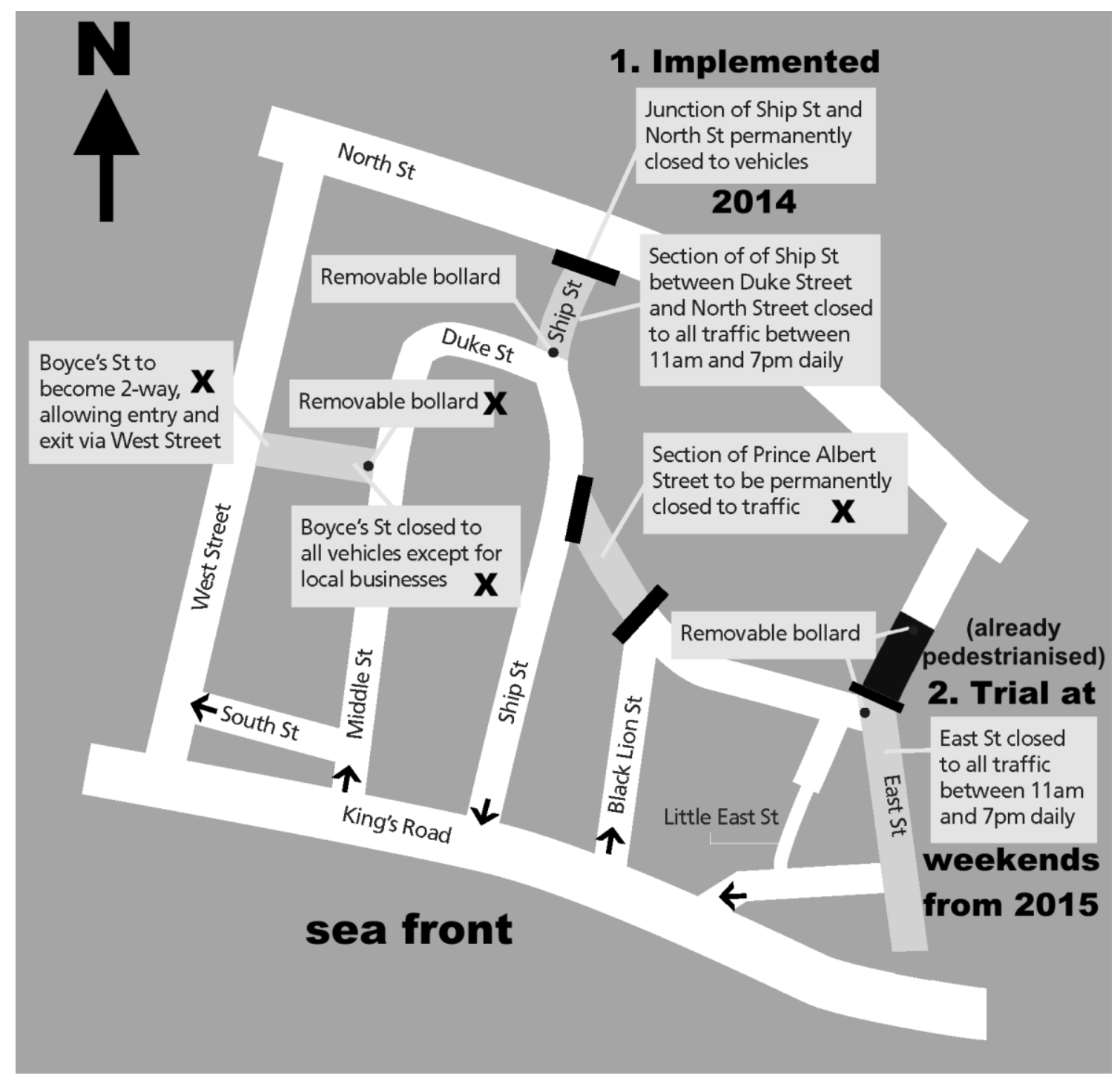

Figure 32012 Proposal for Brighton Old Town showing elements implemented and not implemented $(X)$

\section{$4 \quad$ Methodology}

The study used three methods: traffic counts, a before and after street-based survey and interviews with key stakeholders.

On-street surveys of pedestrians in the Old Town were conducted on a single day in June 2013 and on two days in late June 2015. The original intention was to conduct two comparable 
surveys on weekdays at similar times of the year (both with good weather) before and after the interventions in order to make like-for-like comparisons. Following the decision to begin a trial pedestrianisation of East Street at weekends only, it was also decided to conduct a third survey on a Saturday, to assess the impact of the trial. Some of those findings are also compared with the 2013 baseline in the next section, although the differences cannot necessarily be attributed to the intervention.

The questionnaires were designed to assess: why respondents were in the Old Town, how they travelled there, their views of the area and their views on the changes to the road layouts. A structured random sampling method was used; the surveyors were instructed to approach every 5th person who passed them in either direction.

Stakeholder interviews were conducted in person with business owners who favoured and opposed the scheme, the council officer overseeing the scheme and the lead councillors responsible for transport in 2013 and 2015; some additional interviews with business owners were also conducted in person and by telephone. The aims of the stakeholder interviews were to explore the impact of the changes on businesses and to provide an understanding of the implementation process.

\section{$5 \quad$ Traffic Counts}

Manual traffic counts were conducted from 9am until 5pm on a weekday in June 2013 and a weekday in November 2015. The counts were conducted on the three entry points to the Old Town in 2013 and the two remaining entry points in 2015 after Ship Street was closed to motor traffic.

\begin{tabular}{|l|l|l|l|l|l|l|l|l|l|l|}
\hline & Ship St. & \multicolumn{2}{|l|}{ Black Lion Street } & \multicolumn{3}{l|}{ Middle Street } & \multicolumn{2}{l|}{ Total } \\
\hline & 2013 & 2013 & 2015 & Change & 2013 & 2015 & Change & 2013 & 2015 & Change \\
\hline \multirow{2}{*}{ Cars } & 270 & 254 & 326 & $+28 \%$ & 377 & 528 & $+40 \%$ & 901 & 854 & $-5 \%$ \\
Vans & 104 & 140 & 160 & $+14 \%$ & 140 & 320 & $+129 \%$ & 384 & 480 & $+25 \%$ \\
Lorries & 21 & 35 & 32 & $-9 \%$ & 146 & 73 & $-50 \%$ & 202 & 105 & $-48 \%$ \\
All & 408 & 429 & 518 & $+21 \%$ & 663 & 921 & $+39 \%$ & 1500 & 1439 & $-4 \%$ \\
\hline
\end{tabular}

\section{Table 1 Motor Traffic Counts before and after the changes}

Some caution needs to be exercised when interpreting Table 1 as the daily variability in traffic levels was not known and the traffic counts were conducted at different times of the year, unlike the street surveys. It suggests that there was some internal displacement of traffic within the Old Town, from Ship Street onto Black Lion Street and Middle Street (see Figure 3 above). The overall volume of motor traffic entering the Old Town fell by just $4 \%$. The reduction would have been greater without the big increase in van traffic, which cannot be attributed to the Traffic Improvement Scheme; the general economic improvement over those years and changing 
patterns of deliveries to businesses and residential properties are the most likely causes. National road traffic estimates showed a 6\% increase in the volume of van traffic in 2014 compared to 2013 with the increase appearing to accelerate from 2012 onwards (DfT, 2015). The big fall in the volume of lorries may also reflect changes in delivery practices and there could also be a seasonal effect, although it is likely that the closure of Ship Street removed some lorries that previously passed through the Old Town.

\section{$6 \quad$ Survey Findings}

Two hundred and eighty (280) valid questionnaires were completed in 2013, 219 on the weekday in 2015 and 218 on the Saturday. The proportion of visitors from outside Brighton and the surrounding area (BN, RH and TN postcodes) was considerably higher on the Saturday when they formed a small majority - than in either of the weekday surveys.

Visitors were asked why they were in the Old Town; two of the categories were functional i.e. working or visiting the Council (which has an office in the area) or public services. The proportions of visitors ticking one or both of these functional categories were: $32 \%$ in $2015,50 \%$ on the weekday in 2015 and $10 \%$ on the Saturday. The other main purposes were 'tourism or just wandering', shopping, visiting a café or bar or staying in a hotel.

Car availability (62\% always, $18 \%$ sometimes) was highest amongst weekend visitors, who were also more likely to be employed full-time, which suggests that a higher proportion of affluent visitors from outside the area visit at weekends.

Table 2 shows the modes of travel for visitors to the Old Town in the three surveys. Chi-square tests were performed for each of the main modes of travel as a binary variable (e.g. "proportion cycling' cross-tabulated with 'proportion of other modes'). The higher rate of cycling in 2015 was statistically significant $(\rho<0.001)$ whereas the differences in travel by car $(\rho=0.148)$ and on foot were not $(\rho=0.318)$. The higher level of train travel at the weekend was statistically significant $(\rho<.001)$ and reflects the greater distances travelled by weekend visitors.

\begin{tabular}{|l|r|r|r|r|r|r|}
\hline & \multicolumn{2}{|c|}{2013} & \multicolumn{2}{|c|}{2015 week } & \multicolumn{2}{|c|}{2015 Saturday } \\
\hline Car or van as driver & 47 & $24.4 \%$ & 60 & $30.9 \%$ & 66 & $35.7 \%$ \\
Car or van as passenger & 10 & $5.2 \%$ & 3 & $1.5 \%$ & 4 & $2.2 \%$ \\
On foot & 48 & $24.9 \%$ & 40 & $20.6 \%$ & 27 & $14.6 \%$ \\
Train & 33 & $17.1 \%$ & 21 & $10.8 \%$ & 55 & $29.7 \%$ \\
Bus & 47 & $24.4 \%$ & 46 & $23.7 \%$ & 27 & $14.6 \%$ \\
Cycle & 3 & $1.6 \%$ & 16 & $8.2 \%$ & 3 & $1.6 \%$ \\
Other & 5 & $2.6 \%$ & 8 & $4.1 \%$ & 3 & $1.6 \%$ \\
Valid responses: & 193 & $100.0 \%$ & 194 & $100.0 \%$ & 185 & $100.0 \%$ \\
\hline
\end{tabular}




\section{Table 2 Mode of travel to the Old Town (visitors only)}

Those who had driven to the Old Town, were asked where they had parked. The number of people who parked on the streets of the Old Town was very small: five or six in each of the three surveys, representing less than $3 \%$ of visitors.

\begin{tabular}{|l|r|r|r|r|r|r|}
\hline & \multicolumn{2}{|c|}{2013} & \multicolumn{2}{|c|}{2015 week } & \multicolumn{2}{c|}{2015 Saturday } \\
\hline On street in Old Town & 6 & $5.3 \%$ & 6 & $5.3 \%$ & 5 & $3.7 \%$ \\
On street elsewhere & 7 & $6.1 \%$ & 4 & $3.5 \%$ & 7 & $5.2 \%$ \\
In multi-storey & 24 & $21.1 \%$ & 42 & $37.2 \%$ & 43 & $32.1 \%$ \\
Elsewhere off-street & 20 & $17.5 \%$ & 4 & $3.5 \%$ & 12 & $9.0 \%$ \\
Valid responses: & 57 & $50.0 \%$ & 57 & $50.4 \%$ & 67 & $50.0 \%$ \\
\hline
\end{tabular}

Table 3 Parking locations of visitors who arrived by car

The higher proportion of people parking in the multi-storey car parks in 2015 may have been influenced by the temporary closure of Black Lion Street (see Figure 3) with access only allowed to a multi-storey car park located there. This could have persuaded more drivers to choose this option instead of searching for an on-street space (although most of them would have to leave the Old Town if they wanted to find an on-street alternative).

Participants were asked a range of questions about their perceptions of the Old Town as a place to visit. A five point Likert Scale was used to gauge opinions on five statements about the Old Town. Table 4 shows the proportions who agreed with each of the statements in each of the three surveys; there was little disagreement with any of the statements, apart from the last one about traffic. Residents were more likely than visitors to express concern about traffic; across the three surveys, $60 \%$ of residents agreed that there was too much traffic in the Old Town compared to just $43 \%$ of visitors. Interestingly, opinions about the Old Town became less positive during the week in 2015 but more positive at the weekend.

\begin{tabular}{|l|r|r|r|}
\hline & 2013 (reference) & 2015 week & 2015 Sat. \\
\cline { 2 - 4 } I enjoy visiting the Old Town & $96.4 \%$ & $90.8 \%$ & $97.7 \%$ \\
I like the Old Town as a place to shop & $82.7 \%$ & $74.8 \%$ & $91.7 \%$ \\
I like the Old Town as a place to eat or drink & $90.3 \%$ & $85.8 \%$ & $95.4 \%$ \\
The Old Town is a good place for pedestrians & $79.9 \%$ & $77.0 \% *$ & $91.7 \%$ \\
There is too much traffic in the Old Town & $46.0 \%$ & $52.8 \%$ & $41.3 \% *$ \\
\hline
\end{tabular}

Table 4 Proportion of respondents agreeing or strongly agreeing with statements ( ${ }^{*}$ not significantly different from 2013 at 95\% confidence level - see Appendix for details) 
As the characteristics of the three samples differed in several respects regression analyses were performed to assess whether the differences summarised in Table 4 remained statistically significant after controlling for participant characteristics. Five ordinal regressions were performed using the Likert scale responses as the dependent variables and the following independent variables:

- the survey date (with 2013 as the reference category)

- resident/visitor,

- gender

- employment status

- car availability

The responses summarised in the second and third columns of Table 4 were all significantly different from the 2013 reference case (at the 95\% confidence level), apart from the two that are asterisked. The full regression outputs are shown in the Appendix.

In 2013, before the scheme was implemented, awareness of the proposed changes was low, both amongst visitors, and more surprisingly, amongst local residents. Those who said they were unaware of the proposals were shown a copy of the map produced by the Council which illustrated the proposed changes (Figure 3 without the annotations in black). All respondents were then asked whether they thought the Council was right to propose these changes; $80 \%$ of visitors and $68 \%$ of residents responded 'yes'.

Respondents in 2015 were asked whether they agreed with the changes made to the streets. In those surveys residents were more positive about the changes than visitors; $74 \%$ of residents were in favour, whilst just $39 \%$ of the weekday visitors and $64 \%$ of weekend visitors agreed with the changes. The differences were mainly due to the 'don't know' category; very few people disagreed with the changes, so the more positive views of the residents might simply reflect their greater familiarity with the changes.

Thirty percent $(30 \%)$ of respondents agreed that they noticed less traffic on the streets of the Old Town since Ship Street was pedestrianised. Agreement was slightly stronger amongst the weekend respondents, who may also have been influenced by the closure of East Street. Only $7 \%$ of respondents stated that the changes had caused them any inconvenience. $35 \%$ of weekend respondents agreed that 'the changes have made me more likely to visit the area'. $54 \%$ of respondents (in the Saturday survey only) disagreed with the suggestion that East Street should be reopened to motor traffic on weekends; only $10 \%$ agreed. $34 \%$ of respondents (in both 2015 surveys) agreed that the pedestrianisation of East Street should be extended to weekdays, compared to $23 \%$ who disagreed. 


\section{$7 \quad$ Interview Findings}

The semi-structured interviews conducted with stakeholders explored their views about the proposals, the changes that were made and the process followed. The planning inquiry obliged supporters and opponents of the scheme to consider and articulate their positions and it also prompted several reflections on the implementation process.

Resistance to schemes that might impede or remove traffic from a business and retail environment are common - particularly from business representatives and owners. The principle opponents of the proposed changes were an organisation called the 'Lanes Traders' (said to have around 70 members, representing businesses in The Lanes pedestrianised area), as well as people living in a large block of flats at the southern end of East Street and representatives of the taxi trade in Brighton. A group of businesses in East Street - which does not form part of the constituency of the Lanes Traders - were the main supporters of its pedestrianisation. The groups differed in the type of business represented, with jewellery and other specialist shops in The Lanes as opposed to mostly chain retailers and restaurants / cafes in East Street. Thus the council was faced by opposing business groups on either side of the argument.

Deliveries and customer parking were key opposition issues, although for the Lanes Traders this was in respect of deliveries to them, not the businesses in East Street which had the advantage of varying degrees of rear access to their premises. The closure of Ship Street also created a detour for business owners who had previously driven into the area from the north, a point made by the Lanes Traders' spokesperson. Other arguments against the original proposals included the ability of clients to reach services (such as solicitors) based in the Old Town and the displacement of traffic onto surrounding streets. Concerns were raised about vehicles diverted from East Street onto Little East Street, a narrower road (see Figures 3 \& 5).

Access, by vehicle and on foot, were key issues for both the residents in the flats and for the taxi trade. Opponents argued that restaurants and cafés siting tables and chairs along East Street would impede pedestrians, particularly those in wheelchairs or with children. However, several of the opponents said they were not opposed to the principles of pedestrianisation or traffic removal. The earlier pedestrianisation of The Lanes (Figure 1) was seen to be very successful and there was praise for a shared space scheme nearby, New Road, which was completed in 2007. There was also broad acceptance of, and support for the other pedestrian and weekend closure schemes in Brighton which were seen to contribute to the atmosphere and ambience of the city.

One issue which emerged in many of the interviews was uncertainty surrounding the policy context and the reasons why the Council was proposing the changes. There was a perception, 
both amongst opponents and some supporters of the changes that the process was piecemeal and uncoordinated. For the opponents, the apparent lack of a grand vision or plan for the whole area was an important element of their argument against the proposals. They claimed that such a vision was needed to address the needs of tourists, residents and businesses across the area.

When asked about the Council's motivations for these changes, some interviewees mentioned existing walking and pedestrianisation strategies, and a 'legibility strategy' for the city. The original report to councillors (Brighton \& Hove CC, 2012) referred to a 'Walking Network Strategy' but that document was not available online. A 'Draft Walking Strategy' dated 2003 was the only document identifiable from an online search in 2015. The proposed changes were presented to councillors in a series of reports to committees, but these were detailed operational documents rather than broader longer-term strategies.

Those in favour of the changes were more accepting of the step-by-step approach taken so far. From the local authority perspective the limited monies available for such schemes meant taking opportunities as and where they were available, making 'incremental changes'. Supporters of the East Street closure saw these as "stepping stones" towards a more extensive plan although they also wanted to see wider public realm improvements.

Another perceived complication arising from the fragmented approach related to consultation with the public and other stakeholders over the changes being proposed. Some interviewees criticised the consultation process. Repeated consultation exercises were seen to lead to confusion, which might have deterred some people from engaging. The consultation exercises were perceived to be lacking both a wider 'master planning' opportunity for the public and also some of the specific details, which could have been discussed with specific groups.

For both supporters and opponents, the planning inquiry process was seen as unnecessarily adversarial and a poor use of scarce funds, which would have been better used in implementation. Interestingly one interviewee said it gave the impression that the council was trying to do something "wrong and underhand". The Council officer who was the sole witness for the authority at the inquiry believed with hindsight that this was a mistake - that other officers, such as the highway engineers and road safety specialists should also have given evidence. Although not all of the proposed changes have been implemented, some interviewees suggested that the public perception was that the streets in the area were already pedestrianised (see Fig 4); at the height of the tourist season it is difficult to drive on some of these streets because of pedestrian numbers. 


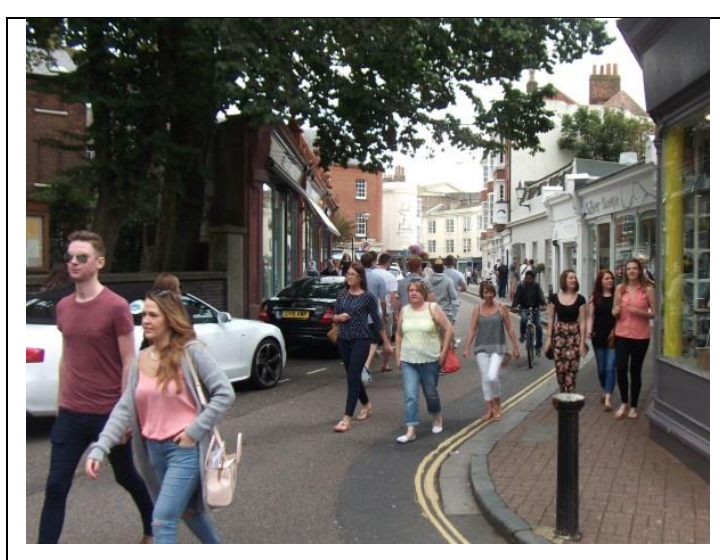

Figure 4 Prince Albert St (open to through traffic but heavily used by pedestrians)

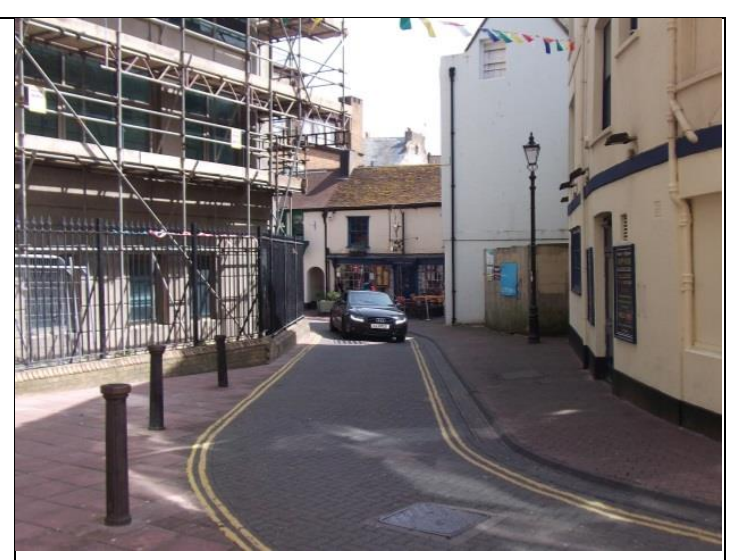

Figure 5 Little East Street (alternative route when East Street is closed to cars)

Following the implementation of the trial weekend closures in East Street there was strong support for the changes from cafes and restaurants who were able to site tables and chairs on the street, although other retailers were also taking advantage of space in the street; some of them also expressed support for extending the trial pedestrianisation to weekdays. Even those who did not specifically benefit did not express concerns over deliveries or access for customers. Support was not unanimous though; some premises in Little East Street expressed concerns about safety for their customers because of traffic diverted from East Street during the weekend closures (see Fig 5).

\section{Discussion}

Traffic and displacement: The only evidence of modal shift comes from the higher proportion of people cycling to the Old Town on the weekday, although with relatively small numbers, not too much weight should be attached to that finding. The traffic counts suggest that the volume of through traffic removed by the closure of Ship Street was relatively small, when measured across the whole day (the 2008 survey was based on a two-hour count in the morning rush hour, when the proportion of through traffic may have been higher). There was clearly some displacement of local traffic from Ship Street onto Black Lion Street and Middle Street but the traffic reduction caused by the Ship Street closure was probably greater than the $4 \%$ fall registered because other factors were increasing local traffic, particularly vans. There are several possible reasons for this; the general economic improvement since 2013 may have increased the number of deliveries to businesses and also contributed to building and renovation work, which was observed to be taking place during 2015.

Concerns around deliveries and customer access to premises were raised by some interviewees, but most of these issues appear to have been allayed through the timing of closures, provision of additional loading bays and perhaps changes in behaviour by some traders (e.g. scheduling deliveries before street closures). 
Some interviewees, particularly the opponents of the changes, pointed to traffic displacement onto surrounding streets. Some taxi journeys, which used to follow Ship Street, are now obliged to travel further, via Kings Road. The Ship Street closure also removed a signal-controlled turn, which increases the flow and speed of the buses using a main road that borders the Old Town (already perceived to be travelling too fast by the spokesperson for the Lanes Traders). Some more significant road schemes are still being developed in the city, including one affecting another road close to the Old Town. The implications for the area remain to be seen, but once again they highlight the importance of an area-wide plan.

Public Perceptions: The general public questioned on the streets were broadly favourable to the changes and more of them favoured seven-day pedestrianisation of East Street than opposed it. Visitors and residents generally express favourable views about the Old Town but Table 4 and the following analysis present an unexpected pattern of changes since the baseline study. During the week, perceptions of too much traffic have worsened since 2013. On some of the streets (Middle Street and Black Lion Street) that perception is accurate, although across the Old Town as a whole the volume of traffic has not substantially changed.

The different composition of the populations surveyed do not explain the more favourable perceptions at the weekend, nor the less favourable perceptions during the week.

Psychological studies have demonstrated that people tend to make judgements in relative rather than absolute terms (see Ariely, 2008 for example), so the more positive perceptions of the pedestrianised environment on East Street at the weekends may have unconsciously worsened people's perceptions during the rest of the week.

\section{Conclusions}

The literature suggests three main benefits from pedestrianisation and/or traffic removal in urban areas: increasing retail spending, improving the urban environment and achieving modal shift. Common concerns, which often disrupt or prevent such changes include: traffic displacement, inconvenience for drivers and perceptions that reduced vehicular access will harm local businesses. This case study found positive business perceptions on the newlypedestrianised road with objections mainly coming from businesses less directly affected by changes to vehicular access. The general public were mainly favourable to the scheme and many would prefer the Council to go further, by pedestrianising East Street on weekdays.

The worst fears about the impacts of the scheme have not materialised; the impact on deliveries, in particular, has proved to be manageable. The very small proportion of people parking in the immediate area illustrates how fears about on-street parking removal are often exaggerated. On the other hand, there was little evidence of the scheme causing any modal shift. The volume of through traffic removed by the closure of Ship Street was relatively small, 
which implies that traffic displacement onto surrounding streets will also have been fairly small. This suggests a paradox: that road closures are easier to implement where volumes of through traffic are already low, but the benefits of traffic removal in such circumstances will be correspondingly limited.

The implemented scheme was the result of several compromises. Some of these were made in response to the planning inquiry recommendations but the changes also responded to the concerns of objectors. The public perceptions that traffic had worsened during the week but improved at weekends suggests that compromising in such circumstances may produce an unsatisfactory outcome for all concerned. Step-by-step implementation may be unavoidable when local authority funding is constrained but this may risk disappointing a public that has already seen more extensive schemes implemented elsewhere.

Even with considerable support for pedestrianisation and traffic removal amongst the public and within some parts of the business community, there were still delays and obstacles to delivering the partial scheme. This study suggests that authorities considering pedestrianisation or road closure need to anticipate such obstacles and only proceed where the political will exists to overcome them. As illustrated in other circumstances by Melia (2015), to obtain the greatest expost benefits (including the most positive ex post perceptions), authorities need to plan for visible improvements to the urban environment, standing firm against ex-ante opposition and avoiding compromises, which dilute the benefits of the scheme.

One other conclusion which would be relevant for other authorities considering similar changes is that an area-wide plan, visibly maintained on an authority's website, can help to address some potential criticisms and strengthen the case when projects are subject to formal inquiry. If funding only allows for piecemeal changes, these can at least be set in a broader, longer-term context.

\section{References:}

Ariely, D. (2008) Predictably Irrational : The Hidden Forces that Shape our Decisions [online]. London: HarperCollins Pub.

Brighton \& Hove CC, (2012) Transport Committee October 2nd Agenda Item 23 Old Town Transport Plan [online]. www.brighton-hove.gov.uk: [Accessed January 2013].

Cairns, S., Atkins, S. and Goodwin, P. (2002) Disappearing traffic? The story so far. Municipal Engineer. 151 (1), pp. 13-22. 
Chung, J., Yeon Hwang, K. and Kyung Bae, Y. (2012) The loss of road capacity and selfcompliance: Lessons from the Cheonggyecheon stream restoration. Transport Policy. $21 \mathrm{pp}$. 165-178.

Chung, Y.Y. (2011) The impact of a pedestrianisation scheme on retail rent: an empirical test in Hong Kong. Journal of Place Management and Development. 4 (3), pp. 231-242.

Civitas Caravel, (2014) Integrated Access Restriction Strategy in Burgos - Final Evaluation. [online]. http://www.civitas.eu/sites/default/files/CARAVEL\%20\%20BURGOS\%20MERT\%2006.02.pdf: [Accessed February 2015].

Civitas Modern, (2013) Superblocks Concept for Access Restrictions in Vitoria-Gasteiz. [online]. http://www.civitas.eu/sites/default/files/modern vg m05.01 0.pdf: [Accessed February 2015].

DfT, (2015) Road Traffic Estimates in Great Britain: 2014 Table TRA0101 Road Traffic (Vehicle Miles) by Vehicle Type in Great Britain, Annual from 1949 [online]. www.gov.uk: Department for Transport. [Accessed November 2015].

Guiver, J. (2011) Travel Adjustments After Road Closure: Workington. In: Anon. (2011) Universities Transport Study Group Conference. Milton Keynes, January.

Hass-Klau, C. (2015) The Pedestrian and the City. New York: Routledge.

Hass-Klau, C. (1993) Impact of pedestrianization and traffic calming on retailing: A review of the evidence from Germany and the UK. Transport Policy. 1 (1), pp. 21-31.

Hunt, J., Brownlee, A. and Stefan, K. (2002) Responses to Centre Street Bridge Closure: Where the" Disappearing" Travelers Went. Transportation Research Record: Journal of the Transportation Research Board. (1807), pp. 51-58.

Melia, S. (2016) The EVIDENCE project: Measure no.4 - Access restrictions. World Transport Policy \& Practice. 22 (1/2), pp. 39-46.

Melia, S. (2015) Urban Transport without the Hot Air. Cambridge: UIT Cambridge.

Parkhurst, G. (2003) Regulating Cars and Buses In Cities: The Case Of Pedestrianisation in Oxford. Economic Affairs. 23 (2), pp. 16-21.

Tsubohara, S., (2007) The Effect and Modification of the Traffic Circulation Plan (VCP)-Traffic Plannign in Groningen in the 1980s. Report number: 317.Groningen: Urban and Regional Studies Institute.

Zhu, S., Levinson, D., Liu, H.X. and Harder, K. (2010) The traffic and behavioral effects of the I35W Mississippi River bridge collapse. Transportation Research Part A: Policy and Practice. 44 (10), pp. 771-784. 